\title{
As pesquisas sobre Educação Ciência, Tecnologia e Sociedade/Ambiente e alfabetização científica e tecnológica socializadas no ENPEC (2011-2017)
}

Researches about Science Technology and Society/Environment education and scientific and technological literacy socialized at ENPEC (2011-2017)

\author{
Bruna Garcia ${ }^{1}$ \\ Alinne Pereira de Oliveira² \\ Leonir Lorenzetti ${ }^{3}$ \\ Marcos Aurelio Zanlorenzi ${ }^{4}$
}

\section{Resumo}

O estudo teve como objetivo analisar as produções socializadas no Encontro Nacional de Pesquisa em Educação em Ciências no período de 2011 a 2019 com foco na linha temática que discute Alfabetização Científica e Tecnológica, abordagens CTS/CTSA e Educação em Ciências. A pesquisa caracteriza-se como bibliográfica, do tipo "Estado da Arte", na qual foram analisados 303 artigos, sendo que, desses, 241 são trabalhos referentes a CTS/CTSA e 62 são trabalhos de AC/ACT. Os descritores da pesquisa foram: número de autores; vertente teórica; origem dos trabalhos; produção por região; enfoque metodológico e instrumentos de pesquisa; área do conhecimento; nível de ensino; sujeitos da pesquisa e referencial teórico utilizado pelos autores. Percebe-se uma predominância de pesquisas que utilizam a vertente teórica CTS e AC, bem como um número maior de trabalhos realizados na região Sul e Sudeste do Brasil e com sujeitos alunos do Ensino Médio. Evidencia-se algumas tendências e desafios nas produções mapeadas, sendo esperado que a pesquisa realizada possa trazer contribuições dialógicas para o Ensino de Ciências.

Palavras chaves: Estado da Arte; Ciência-Tecnologia-Sociedade-Ambiente; Alfabetização-Científica e Tecnológica; Educação em Ciências.

\section{Abstract}

The study aimed to analyze the socialized productions at the National Research Meeting in Science Education from 2011 to 2019, focusing on the thematic line that discusses Scientific and Technological Literacy CTS / CTSA approaches and Science Education. The research is characterized as bibliographic of the type "State of the Art", in which it analyzed 303 articles, being 241 works related to CTS / CTSA and 62 works of AC / ACT. The research descriptors were: number of authors; theoretical side; origin of the works; production by region; methodological approach and research tools; knowledge area; level of education; research subjects and theoretical framework used by the authors. There is a predominance of research that uses the theoretical aspect CTS and AC, as well as a greater number of studies carried out in the south and southeast regions and with high school students. Some trends and challenges in mapped productions are evidenced, and it is expected that the research carried out can bring dialogical contributions to Science Teaching.

Keywords: State of Art; Science-Technology-Society-Environment; Scientific-Literacy and Technologic; Science Education.

\footnotetext{
${ }^{1}$ Universidade Federal do Paraná | klebisbruna@gmail.com

${ }^{2}$ Universidade Federal do Paraná | alinnep1990@gmail.com

${ }^{3}$ Universidade Federal do Paraná | leonirlorenzetti22@gmail.com

${ }^{4}$ Universidade Federal do Paraná | marcos.zan@terra.com.br
} 


\section{Introdução}

O Ensino de Ciências tem se ocupado com múltiplos desafios que permeiam a sociedade atual. Tais enfrentamentos vêm sendo abordados em vários estudos no campo da Ciência, Tecnologia e Sociedade (CTS), os quais exprimem relações com diversos campos do conhecimento (SANTOS; MORTIMER, 2002; SANTOS, 2012), especialmente por fatores históricos e curriculares da área. No entender de Auler e Bazzo (2001) o movimento que emergiu no contexto nacional, ainda apresenta obstáculos a serem superados no contexto educacional em relação aos objetivos centrais do aspecto CTS, essencialmente quando se refere aos desafios de colocar a tomada de decisão em uma perspectiva mais democrática. Ressalta-se a importância de repensar o currículo com base nos pressupostos da Educação CTS e suas reconfigurações para que forneça parâmetros e orientações com elementos bem delineados, a fim de adotar um Ensino em uma compreensão crítica e reflexiva no contexto científico-tecnológico e suas relações com a sociedade (SOUSA, 2012).

Desta forma, emergem também os desafios com a formação inicial de professores que, apesar das inúmeras complexidades de aproximações curriculares com a educação CTS, demanda por uma formação para maior inserção social das pessoas nos processos de tomada de decisões, conscientes e aptas a participarem de assuntos que envolvam a ciência e a tecnologia (CASSIANI; LINSINGEN, 2009). Em linhas gerais, trata-se de tornar o papel dos sujeitos como atores e participantes ativos das mudanças e transformações da sociedade na qual vivem. Estudos também apontam que desenvolver pesquisas com professores pode contribuir para entender "por quais processos se pode auxiliar os sujeitos em formação inicial ou continuada a compreender e a realizar o Ensino" (PIMENTA; LISISTA, 2004, p. 95). Contudo, ainda se percebe um enorme esforço para modificar o Ensino de Ciências no que se refere à formação de professores e às novas tendências de Ensino (CACHAPUZ; PAIXÃO, 1999).

Responder a tais desafios requer ações transformadoras por parte dos espaços formativos, que perpassam pelo reconhecimento da função social dos sujeitos envolvidos, e que demandam por mudanças de postura e dos objetivos pedagógicos em sala de aula (SANTOS, 2007). Essas ações inter-relacionadas com a Educação CTS possibilitam abordagens metodológicas contextualizadas e implicam em encaminhamentos pedagógicos interdisciplinares no Ensino de Ciências. Nesta perspectiva, as atitudes que abrem espaços de diálogos problematizadores e críticos perpassam pela Alfabetização Científica e Tecnológica (ACT) na qual os sujeitos possam realizar as leituras de mundo (CHASSOT, 2003). Portanto, entende-se que o Ensino de Ciências possibilita a promoção da $A C T$, pois parte-se da premissa que na dinâmica social crescente, vinculada aos avanços científicotecnológicos, é fundamental a democratização de uma sociedade que seja alfabetizada científica e tecnologicamente (AULER; DELIZOICOV, 2001). Para que tais avanços se efetivem, torna-se necessário uma reflexão séria acerca da importância de currículos pautados por uma perspectiva crítica, o que implica, também, em uma mudança nas políticas de formação inicial e continuada dos professores.

No intuito divulgar e socializar a pesquisa em Educação em Ciências é que foi criado em 1997 o Encontro Nacional de Pesquisa em Educação em Ciências (ENPEC), um evento bienal promovido pela Associação Brasileira de Pesquisa em Educação em Ciências (ABRAPEC) sendo considerado um dos maiores eventos na área de Educação em Ciências no Brasil. Trata-se de um evento que integra uma ampla comunidade de educadores e pesquisadores das áreas de Educação em Química, Física, Biologia e áreas correlatas, 
enfocadas isoladamente ou de maneira interdisciplinar, com a finalidade de discutir trabalhos de pesquisa recentes e tratar de temas de interesse da ABRAPEC. Dentre as atividades programadas para o evento destacam-se: mesas-redondas; conferências; sessões de apresentação de trabalhos completos no formato de pôsteres; rodas de conversa e encontros. Informações adicionais a respeito do evento serão divulgadas em circular específica. O público-alvo do ENPEC é formado por interessados na pesquisa em Educação em Ciências da Natureza e áreas correlatas, incluindo professores-pesquisadores da Educação Básica e Superior, estudantes de pós-graduação, estudantes de licenciatura, formadores de professores e pesquisadores.

É por conta dessa importância atribuída ao evento que elencamos como objetivos deste artigo: identificar, descrever e analisar a produção socializada no ENPEC, no período em que foram realizadas as edições de XIII a XI (2011-2017), a partir da linha temática que tem como centralidade os enfoques CTS e ACT na Educação em Ciências. Para além da análise quantitativa, entendemos como fundamental compreendermos como a linha temática vem se constituindo ao longo do período analisado.

\section{Aspectos Metodológicos}

A pesquisa é de natureza quanti-qualitativa e caracteriza-se como um estudo bibliográfico (GIL, 2008). Utilizou-se da metodologia do tipo "Estado da Arte" que, segundo Ferreira (2002), tem o desafio de mapear e de discutir uma certa produção acadêmica em diferentes campos do conhecimento, tendo como objetivo analisar e compreender como se constituem as pesquisas em determinado período.

O corpus da pesquisa envolveu a leitura e análise de 303 trabalhos publicados no VIII, IX, X e XI do ENPEC, no período de 2011 a 2017. Optou-se por esse recorte temporal, devido ao surgimento das linhas temáticas no período analisado, assim o trabalho permite evidenciar como as pesquisas têm se constituído ao longo deste marco inicial.

A linha temática analisada teve pequenas mudanças na denominação no período analisado (Quadro 1), no qual é possível constatar a inclusão da nomenclatura "CTSA" e a mudança de "Ensino" para "Educação em Ciências".

Quadro 1 - Denominação da Linha temática 9 no período de 2011 a 2017.

\begin{tabular}{|c|c|}
\hline ENEPC & Nome da linha temática \\
\hline VIII & Alfabetização científica e tecnológica, abordagens CTS e Ensino de Ciências \\
\hline IX & Alfabetização científica e tecnológica, abordagens CTS e Ensino de Ciências \\
\hline$X$ & Alfabetização científica e tecnológica, abordagens CTS e CTSA e educação em Ciências \\
\hline IX & Alfabetização científica e tecnológica, abordagens CTS/CTSA e Educação em Ciências \\
\hline
\end{tabular}

Fonte: Elaborado pelos autores.

A pesquisa se consolidou por meio de três etapas, a saber: $1^{a}$ etapa: mapeamento das produções da VIII à XI edição do ENPEC, que incluiu todos os trabalhos da linha temática analisada. A $2^{a}$ etapa: elaboração de um banco de dados, por meio do qual realizou-se a leitura sistemática dos artigos levantados, evidenciando os descritores centrais que possibilitam a compreensão do que se pesquisa na área em Educação em Ciências nos últimos anos, sendo: a) número de autores por trabalho; b) vertente teórica; c) origem dos trabalhos; d) distribuição da produção por região; e) enfoque metodológico e instrumentos de pesquisa; f) área do conhecimento; g) nível de Ensino; h) sujeitos da pesquisa; i) 
referencial teórico utilizado pelos autores. E, por último, na $3^{a}$ etapa: realização da análise de conteúdo (BARDIN, 2011) a partir do banco de dados, e que possibilitou caracterizar, quantificar e identificar possíveis tendências das pesquisas em CTS e CTSA, bem como AC e ACT.

\section{Resultados e Discussões}

Em um universo de 5.327 trabalhos aceitos no período de 2011 a 2017, localizou-se 303 artigos na linha temática analisada, constituindo o corpus da pesquisa, conforme Tabela 1.

Tabela 1 - Número de Trabalhos submetidos e aprovados.

\begin{tabular}{ccccccc}
\hline Atas/edições & Submetidos & Aceitos & CTS/CTSA & AC/ACT & Linha temática & $\%$ \\
\hline VIII & 1695 & 1235 & 69 & 12 & 81 & 26,7 \\
IX & 1526 & 1485 & 53 & 12 & 65 & 21,5 \\
X & 1768 & 1272 & 48 & 11 & 59 & 19,5 \\
XI & 1840 & 1335 & 71 & 27 & 98 & 323 \\
\hline Total & 6.829 & 5.327 & 241 & 62 & 303 & 100 \\
\hline
\end{tabular}

Fonte: Elaborado pelos autores

Ao examinar a Tabela 1, percebe-se que a linha temática analisada compreende cerca de 5,7\% do total de trabalhos aceitos no evento. Os trabalhos envolvendo a Educação CTS/CTSA constituem um número bastante expressivo, abrangendo 79,5\% da área estudada, enquanto as produções sobre AC/ACT correspondem 20,5\% da linha temática. Observa-se que na XI edição o número de produções com abordagens AC/ACT duplicou, demonstrando uma tendência no crescimento do campo de pesquisa no último ano. Entretanto, alguns trabalhos (VIECHENESKI; LORENZETTI; CARLETTO, 2015; GARVÃO, 2016; HILÁRIO; SOUZA, 2017) discutem a importância de ampliar as pesquisas sobre AC, de modo a aprofundar as discussões e as reflexões no Ensino de Ciências.

Assim como o trabalho de Slongo, Lorenzetti e Garvão (2015), o estudo identificou uma concentração maior em produções colaborativas, sendo $140(46,51 \%)$ trabalhos elaborados por duas autorias, seguidos por 74 (24,58\%) trabalhos com três autores e 38 (12,62\%) trabalhos com quatro autores. Foram encontradas 15 (4,98\%) produções de caráter individual. Também foram identificados 9 (2,99\%) trabalhos que não apresentavam autoria, provavelmente as versões finais foram enviadas sem a identificação dos autores.

Tabela 2 - Vertente teórica dos trabalhos apresentados.

\begin{tabular}{|c|c|c|c|c|c|c|c|c|c|c|c|}
\hline \multirow{2}{*}{ Edições } & \multicolumn{11}{|c|}{ Vertente teórica } \\
\hline & CTS & CTSA & CTS/CTSA & $n . i^{\star}$ & Total & $\% * \star$ & $A C$ & $\mathrm{ACT}$ & $\mathrm{NI}$ & Total & $\% * \star$ \\
\hline VIII & 34 & 8 & - & 27 & 69 & 28,6 & 9 & 2 & 1 & 12 & 19,4 \\
\hline IX & 36 & 9 & - & 8 & 53 & 22,0 & 10 & 2 & - & 12 & 19,4 \\
\hline$x$ & 35 & 5 & - & 8 & 48 & 19,9 & 10 & - & 1 & 11 & 17,7 \\
\hline$X I$ & 53 & 12 & 2 & 4 & 71 & 29,4 & 22 & 5 & - & 27 & 43,5 \\
\hline Total & 158 & 34 & 2 & 47 & 241 & 100 & 51 & 9 & 2 & 62 & 100 \\
\hline
\end{tabular}


Nos trabalhos analisados identificam-se distintas formas de representar a área com as denominações de CTS, CTSA, ACT e AC, sendo que no período analisado as produções em apoio à vertente teórica CTS e AC são predominantes em relação a CTSA e ACT. Nota-se, a partir da Tabela 2, que as pesquisas denominadas CTS compreendem 65,56\% e, os trabalhos com caráter CTSA correspondem a um total de 14,11\%. Enquanto os trabalhos com a temática AC concentram um total de $82,26 \%$, sendo um valor bastante expressivo se comparado com a linha ACT, que representa apenas $14,52 \%$ das pesquisas mencionadas.

A pesquisa de Luz, Araújo-Queiroz e Prudêncio (2019) verificou os motivos, pressupostos e interesses de trabalhos que marcaram a escolha dos pesquisadores pela denominação da vertente teórica CTS ou CTSA, sendo observado que ainda não existe um consenso na área quanto à compreensão e às características das perspectivas CTS e CTSA. Entende-se que a diferença no número de produções em trabalhos denominados CTSA, possa ser devido à área de estudo ser nova no país, ficando restrita a um pequeno grupo de pesquisadores. Já estudos realizados por Freitas e Ghedin (2015), com o objetivo de realizar um inventário de pesquisas sobre o Estado da Arte em CTS, evidenciaram um crescimento de trabalhos e consideraram uma expansão na área.

Nas pesquisas sobre ensino de Ciências, percebe-se que há autores que têm utilizado diferentes terminologias para referenciar a importância de se preparar o indivíduo para a vida em uma sociedade científica e tecnológica como, por exemplo, Alfabetização Científica (LORENZETTI, 2000; LORENZETTI; DELIZOICOV, 2001; CHASSOT, 2000, SASSERON, 2008), Alfabetização Científica e Tecnológica (FOUREZ, 2004; AULER; DELIZOICOV, 2001) e Letramento Científico (MAMEDE; ZIMMERMANN, 2005; SANTOS, 2007). Segundo Sasseron e Carvalho (2011, p. 60) "podemos perceber que no cerne das discussões levantadas pelos pesquisadores que usam um termo ou outro estão as mesmas preocupações com o ensino de ciências", isto é, têm como mesmo objetivo a promoção de um ensino que fomente benefícios para os sujeitos, a sociedade e o meio ambiente. Embora haja distintas terminologias, autores como Ribas e Broietti (2020) afirmam que a pluralidade semântica não interfere nas discussões levantadas na literatura da área do ensino de Ciências, uma vez que os autores perceberam que o objeto de estudo investigado para realizar o seu trabalho, utilizava "Letramento Científico" como nomenclatura do documento.

Outro descritor analisado foram as instituições de ensino nas quais autores atuam, constatando-se o predomínio de instituições públicas, indicando sintonia com os estudos de Teixeira e Megid Neto (2006; 2017) e Vasco e Zakrzevski (2010). Em relação às IES federais que estão representadas em 232 trabalhos, destacam-se a UFRGS (20,2\%), UTFPR (9,5\%), UFSC (8,2\%), UFRJ (7,3\%), UnB (6,9\%) e UFSM (6,4\%). Com relação às IES estaduais identificou-se 83 trabalhos, constando as seguintes instituições: USP $(22,9 \%)$ e UNESP (22,9\%), em seguida UNICAMP (7,2\%), UESC (6,1\%) e UEM (6,1\%). É notável o número de instituições públicas em produção de pesquisas na área estudada, visto que equivalem a 95,8\% da produção total; os 4,2\% que representam as universidades e faculdades privadas, totalizam 53 trabalhos, que apresentam 20 diferentes instituições, das quais se destacam as seguintes IES: USC (11,5\%), UNICSUL (11,5\%), UFP (7,7\%) e PUC-RJ (7,7\%). Apenas 3 publicações mencionam a participação de instituições municipais, como Núcleos e Secretarias de Educação. 11 trabalhos são de escolas, 2 de instituições estrangeiras e 4 envolvem outras. É interessante constatar que o número de produções analisadas provém de Programas de Pós-Graduação que estão concentrados em polos regionais como Sul e Sudeste do Brasil e, essas instituições citadas, possuem vários campi e unidades específicas de cada área de Programas de Pós-Graduação em Educação, Ensino ou Tecnologia. 
Com base nos dados disponíveis na série analisada, a partir da escala temporal, constata-se que as instituições públicas continuam a constituir um espaço predominante e de excelência na construção de conhecimento no campo examinado. Constatou-se, também, que apenas 20 (5,4\%) dos trabalhos mencionam a participação de escolas, colégios, prefeituras, Secretarias de Educação, entre outros em seus estudos.

A partir dos dados mapeados o estudo buscou contabilizar o número de produções por distribuição regional das últimas quatro edições do ENPEC. Observa-se que a região Sudeste corresponde 42,5\% dos trabalhos, seguida da região Sul com 29,1\% e da região Nordeste com $12,6 \%$.

Tabela 3 - Distribuição dos trabalhos por Região.

\begin{tabular}{ccc}
\hline Região & $n^{\circ}$ produções & Percentual (\%) \\
\hline Norte & 20 & 5,0 \\
Nordeste & 50 & 12,6 \\
Centro-Oeste & 29 & 7,3 \\
Sudeste & 169 & 42,5 \\
Sul & 116 & 29,1 \\
Estrangeira & 4 & 1,0 \\
n.i* & 10 & 2,5 \\
\hline n. ¿ $^{*}$ não identificado. Fonte: Elaborado pelos autores.
\end{tabular}

Percebe-se que existe uma forte concentração nas produções provindas das instituições de origem das regiões Sul e Sudeste que correspondem a 71,7\% da área estudada. A região Nordeste apresentou uma tendência no ano de 2013 (Figura 1) e durante as quatro edições do evento demonstrou um potencial em suas produções no cenário dentro das temáticas analisadas, mesmo com a queda de submissões de trabalhos no ano de 2015. Com respeito à região Norte, mesmo representando uma baixa percentagem $(5,0 \%)$ dentro da linha estudada, evidenciou-se um pequeno crescimento que se expressa no ano de 2013. Nota-se que a região Centro-Oeste obteve uma linearidade crescente em produções contínuas nas quatro edições do ENPEC.

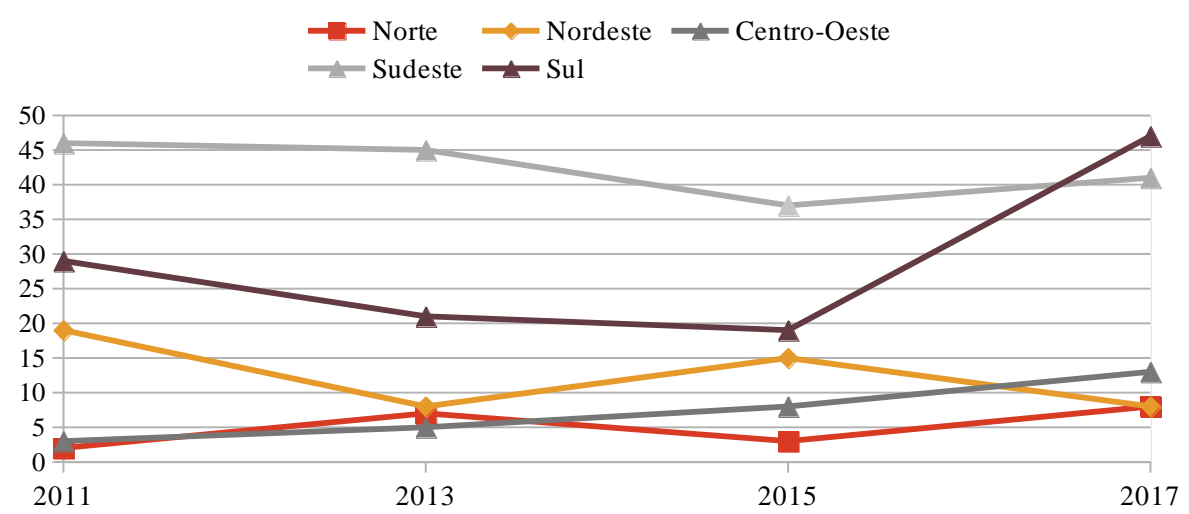

Figura 1 - Distribuições do número de instituições por regiões encontrados no ENPEC (2011-2017). Fonte: elaborado pelos autores.

Estudos como o de Slongo (2004), Lorenzetti (2008) e Teixeira e Megid Neto (2017) demonstram que a centralização da produção acadêmica na região Sul e Sudeste refletem uma desigualdade na distribuição do conjunto de Programas de Pós-Graduação nas diferentes áreas, assim como a desigualdade social e econômica entre as diferentes regiões 
brasileiras. Por fatores até mesmo históricos do Brasil, as regiões Norte, Nordeste e CentroOeste sofrem com a falta de Programas de Pós-Graduação, bem como pela falta de financiamento e investimentos nas instituições de Ensino e em pesquisas (ROSÁRIO; VENTURIERI; GUSMÃO, 2017). Pode-se também associar os custos de participação no evento para os pesquisadores de regiões mais próximas, pois no ano de 2017 o evento do ENPEC foi realizado em Florianópolis - Santa Catarina, onde pesquisadores que atuam em regiões mais próximas como Sul e Sudeste tiverem seus custos diminuídos, comparados às regiões mais distantes como Norte e Nordeste. Já o de 2019 foi realizado em Natal - Rio Grande do Norte, facilitando o deslocamento das regiões Nordeste, Sudeste e Norte.

Com relação ao componente curricular no período analisado, bem como à linha estudada, no que diz respeito aos eixos temáticos CTS/CTSA e AC/ACT observou-se um número expressivo de 17 diferentes campos do conhecimento. Destes dados, 10,6\% referem-se à grande área em Educação em Ciências, sendo que a subdivisão mais representada compete ao Ensino de Ciências (36,0\%), que corresponde a 109 trabalhos, aparecendo em seguida o Ensino de Química (16,8\%) que compreende 51 artigos e o Ensino de Biologia (6,9\%), no qual constatam-se 21 produções que realizaram trabalhos com este foco. Percebe-se, na Tabela 4, que o campo de estudo analisado abrange diversas áreas do conhecimento, sendo bastante significativo, uma vez que amplia a área de discussão das linhas temáticas avaliadas.

Tabela 4 - Número de trabalhos por componente curricular

\begin{tabular}{ccc}
\hline Componente Curricular & $N^{0}$ de trabalhos & Percentual (\%) \\
\hline Ensino de Ciências & 109 & 35,97 \\
Química & 51 & 16,83 \\
Educação em Ciências & 32 & 10,56 \\
Interdisciplinar & 27 & 8,91 \\
Biologia & 33 & 10,89 \\
Física & 20 & 6,60 \\
Educação Ambiental & 5 & 1,65 \\
Outros & 16 & 5,28 \\
n.e* & 10 & 3,30 \\
\hline Total & 303 & 100
\end{tabular}

*n.e: não encontrado. Fonte: Elaborado pelos autores

Observa-se, a partir da Tabela 4, o caráter interdisciplinar nas pesquisas mapeadas, totalizando 27 trabalhos ao longo das quatro edições estudadas, correspondendo 8,9\% das pesquisas realizadas. Entretanto, apesar da frequência, considera-se ainda um campo em discussão e ampliação (FOUREZ, 2003; AUGUSTO; CALDEIRA, 2007; MOZENA; OSTERMANN, 2014) no qual trabalhos promovidos com este caráter interdisciplinar exigem esforço, pois envolvem tempo, muita pesquisa, construção de conteúdo e criação de diálogo, tanto por parte das universidades, como da escola.

No que diz respeito ao nível de Ensino, dos 303 trabalhos analisados na linha temática existe uma concentração maior em pesquisas que desenvolvem trabalhos no Ensino Médio ( $97=31,3 \%)$ e em estudos que foram realizados no Ensino Superior $(55=17,7 \%)$. Com relação ao Ensino Fundamental I e II, nota-se uma discrepância de produções voltadas para esses níveis de Ensino, principalmente no que se refere a Educação Infantil. 
Tabela 5 - Número de trabalhos por nível de ensino.

\begin{tabular}{ccccccc}
\hline ENPEC & \multicolumn{7}{c}{$N^{\circ}$ de Produções } \\
\hline Nível de Ensino & VIII & IX & $X$ & XI & Total & $\%$ \\
\hline Educação Infantil & - & 2 & - & 1 & 3 & 1,0 \\
Ensino Fundamental I & 6 & 5 & 5 & 9 & 25 & 8,3 \\
Ensino Fundamental II & 5 & 9 & 6 & 10 & 30 & 9,9 \\
Ensino Médio & 27 & 21 & 16 & 33 & 97 & 32,0 \\
Ensino Superior & 15 & 12 & 10 & 18 & 55 & 18,2 \\
Pós-Graduação & 4 & - & 3 & 4 & 11 & 3,6 \\
Comunidade & 3 & - & - & 1 & 4 & 1,3 \\
Curso Profissionalizante & 3 & 4 & 1 & 1 & 9 & 3,0 \\
Educação Básica & - & - & 2 & 3 & 5 & 1,7 \\
Educação não-formal & 1 & 1 & 1 & 2 & 5 & 1,7 \\
Outros & 16 & 13 & 13 & 17 & 52 & 17,2 \\
n.i* & 2 & 2 & 1 & 2 & 7 & 2,3 \\
\hline
\end{tabular}

*n.i: não identificado. Fonte: Elaborado pelos autores.

Nota-se que, ao analisar a Tabela 5, o número de pesquisas voltadas para a comunidade é quase inexistente, somando um total de apenas quatro produções (1,3\%). Os estudos que buscaram desenvolver suas pesquisas para além do espaço formal de ensino, isto é, no ensino não-formal, correspondem a cinco produções (1,7\%), o que também revela ser um dado pouco expressivo dentro da linha temática. Cabe ressaltar a importância dos espaços formais, mas para além deles, compreende-se que o aprendizado ocorre também fora dos muros escolares e em outros espaços. Portanto, faz-se necessário desenvolver e promover estudos com abordagens que busquem aproximações com o ensino não-formal, bem como pesquisas com as comunidades possibilitando, de forma dialógica, aproximações com as instituições de Ensino Básica e das instituições do Ensino Superior.

Com relação às metodologias destacaram-se estudos de caráter Teórico e Documental (59,3\%), como as mais utilizadas, incluindo: (a) Pesquisa Teórica (35=18,5\%): estas pesquisas tiveram como preocupação principal provocar uma reflexão a partir de referências teóricas, problematizando e evidenciando os questionamentos em temas centrais como formação de professores, Ensino e aprendizagem, contextualização, entre outros; (b) Pesquisa Documental $(25=13,2 \%)$ : estes estudos tinham como objetivo central analisar materiais ou recursos didáticos usados por instituições de Ensino e/ou analisar periódicos ou anais dos eventos científicos; (c) Estado da Arte (22=11,6\%): estes estudos tiveram como foco o levantamento de artigos em revistas científicas para verificar mudanças ou transformações de forma quantitativa e/ou qualitativa das pesquisas em um campo específico do conhecimento. Foram incluídos nos dados as pesquisas também consideradas como revisão bibliométrica; (d) Intervenção pedagógica (14=7,4\%): o caráter destas pesquisas era a realização de estudos a partir de uma instituição de ensino que tem por objetivo analisar mais o processo do que o resultado; (e) Estudo de caso (14=7,4\%): pesquisas com esse caráter tiveram como objetivo realizar a investigação de uma, ou mais, problemática específica evidenciando, por meio de seus estudos, o tema emergente; ( $f$ ) Revisão de Literatura $(13=6,8 \%)$ : estas pesquisas se constituíram a partir de um universo de referenciais teóricos pertinentes para a temática abordada, com foco em tecer contribuições e problematizações a partir dos dados levantados.

Verificou-se, também, as técnicas de pesquisas utilizadas para a constituição de dados pelos autores, identificando-se que as produções realizam em seus estudos duas ou mais 
técnicas combinadas para a constituição dos dados, a saber: (a) questionário (72=38,5\%); (b) documentos (40=20,5\%); (e) entrevistas ( $26=13,3 \%$ ); (f) filmagens, vídeos (21=10,8\%); (g) relatórios, incluindo diário de bordo e diário de campo (18=9,2\%); (h) sequência didática (18=9,2\%). Todavia, algumas pesquisas utilizaram a metodologia de ensino das sequências didáticas atreladas aos três momentos pedagógicos (ANGOTTI; DELIZOICOV, 1990), entre outros instrumentos como, gravações de áudio, fotografias e grupo focal, porém o estudo priorizou as técnicas que se destacaram majoritariamente, nas quatro edições do ENPEC.

De acordo com Andrade (2007) utilizar técnicas e instrumentos de pesquisas combinadas revela a preocupação dos pesquisadores em olhar o objeto investigado sob diferentes perspectivas e, parece ser mais coerente se tratando de áreas com questões mais complexas. Isso revela que a combinação de entrevistas com grupo focal, por exemplo, ou a elaboração de uma sequência didática com filmagens e vídeos, torna as pesquisas com abordagens mais amplas, garantindo uma maior riqueza nos dados.

Dos 303 artigos analisados, em 185 (61,06\%) dos trabalhos divulgados os autores não apresentaram metodologia. Destaca-se que em 12,13\% das pesquisas os autores mencionaram metodologias de ensino como metodologias de pesquisa, por exemplo, consideraram "Ensino Investigativo", "Ihas Interdisciplinares de Racionalidade", "Investigação Temática", entre outros, como metodologias de pesquisa, o que demonstra um equívoco por parte dos pesquisadores. Em 74 trabalhos (24,42\%) não há registro de técnicas de pesquisas e em 142 trabalhos (46,8\%) não foram encontradas as metodologias de análise. Verificou-se que $62,8 \%$ das pesquisas evidenciaram apenas as etapas e as abordagens realizadas durante a pesquisa, mas não mencionavam a tipologia de pesquisa utilizada. Para André (2010), que considera os elementos da pesquisa um avanço e um desenvolvimento no campo de estudo, ainda há muito a aperfeiçoar para que haja uma contribuição efetiva nos processos, no que se refere ao campo de dados das pesquisas.

Com relação aos sujeitos da pesquisa, os estudos referentes à Educação CTS/CTSA e à temática AC/ACT evidenciaram que 52,5\% foram desenvolvidos com alunos, apenas 9,6\% com professores e 2,3\% trabalhos realizados com professores e alunos. Com relação aos dados observados, foi possível perceber uma discrepância entre as pesquisas realizadas com os alunos e professores, bem como com o nível de ensino no qual foi identificada uma polarização maior em produções que se destinam ao Ensino Médio (31,3\%) e poucos trabalhos destinados ao Ensino Fundamental I e II (18,2\%). Destaca-se que apenas 2,0\% dos estudos realizaram pesquisas voltadas para comunidade. Pesquisas com o objetivo de investigar ou analisar documentos, foram classificados como "outros", isto é, artigos produzidos com foco em analisar ou realizar levantamentos a partir livros didáticos, periódicos científicos, currículos, bem como desenvolver reflexões teóricas a partir da literatura, ou seja, pesquisas de caráter documental, representam 28,7\%. Em 5,0\% dos trabalhos levantados não foi encontrado no corpus do texto a quem a pesquisa era endereçada.

O estudo buscou também evidenciar os referenciais teóricos utilizados pelos pesquisadores para desenvolverem os trabalhos envolvendo a Educação CTS/CTSA e a temática AC/ACT. Os dados referentes aos trabalhos com Educação CTS/CTSA destacam os seguintes referenciais: Décio Auler 12,9\% ( $n=205)$, Wildson Luiz Pereira dos Santos 10,8\% ( $n=171)$, Walter Antônio Bazzo 6,6\% ( $n=105)$, Glen S. Aikenhead 4,1\% $(n=65)$ e José Antônio Acevedo-Díaz 3,2\% ( $n=51$ ). Ressalta-se a predominância de autores nacionais como fontes de referência nas pesquisas dos trabalhos levantados (CHRISPINO et al., 2013; RODRÍGUEZ, PINO, 2019), demonstrando a relevância do país no campo CTS/CTSA. 
A partir da análise dos artigos encontrados relacionados à temática $A C / A C T$, entre os referenciais mais citados identificam-se os seguintes autores: Lúcia Helena Sasseron 24,8\% $(n=39)$, Ana Maria Pessoa de Carvalho 22,9\% ( $n=36)$, Demétrio Delizoicov 17,2\% ( $n=27)$, Leonir Lorenzetti 16,6\% ( $n=26)$, Attico Chassot 14, 1\% ( $n=22)$ e Gerard Fourez 4,5\% ( $n=7)$. Esses dados demonstram a importância dos trabalhos desenvolvidos por esses pesquisadores e o quanto estão contribuindo com as novas investigações na área de Educação em Ciências.

\section{Considerações finais}

Após a análise percebe-se que os dados constituídos oportunizam uma série de reflexões e considerações, visto que as informações explicitadas perpassam por várias instâncias. Compreende-se que a realização do mapeamento da temática envolvida permite a abertura de discussões e debates acerca da grande área em Educação em Ciências e de como as produções têm se evidenciado nos últimos anos em um dos maiores encontros nacionais de pesquisa no campo abordado.

Em linhas gerais, o estudo buscou e realizar um levantamento das últimas quatro edições do ENPEC a partir da linha temática que aglutina trabalhos sobre CTS/CTSA e $A C / A C T$, entende-se a especificidade do estudo no recorte temporal da linha temática mapeada. Percebe-se uma ampliação nas pesquisas conforme o avanço das edições de VIII a XI do evento, no momento que houve a separação das áreas temáticas. Contudo é necessária uma análise mais atenta das problemáticas encontradas nas produções, principalmente no que se refere às suas disposições e na complexidade com a constituição de dados explicitadas durante o estudo.

Entende-se que a qualidade das pesquisas produzidas na Educação CTS/CTSA e na temática AC/ACT enfrenta um grande desafio referente ao aprimoramento teórico, na medida em que alguns autores não se posicionaram frente à escolha da vertente teórica de seus trabalhos.

Quanto à origem dos trabalhos, percebemos a importância de políticas públicas e a necessidade de financiamento em Programas de Pós-Graduação nas regiões como Norte e Nordeste, uma vez que a realização de produções desenvolvidas nestes espaços geográficos poderia ter um maior alcance e visibilidade em suas pesquisas.

Outro ponto importante a ser ressaltado é a problemática de pesquisas que não apresentaram um aprimoramento metodológico em suas produções, visto que evidenciar os encaminhamentos teórico-metodológicos, bem como os as técnicas de pesquisa e metodologias de análises é fundamental, e garante a riqueza das futuras produções.

Reforça-se, mais uma vez, a importância em ampliar o interesse em estudos voltados para os contextos da Educação Infantil e do Ensino Fundamental I e II. Como foi ressaltado durante a análise dos dados, estes níveis de escolarização continuam recebendo uma limitada atenção nas diversas áreas do conhecimento.

Considerando o número expressivo de trabalhos envolvendo a Educação CTS, a linha temática do ENPEC deveria ser denominada de Educação CTS/CTSA e Alfabetização Científica e Tecnológica na Educação em Ciência, visto que existe uma maior produção de trabalhos voltados para o campo Ciência, Tecnologia, Sociedade e Ambiente, se comparado com a Alfabetização Científica e Tecnológica. 
Espera-se que o estudo tenha trazido contribuições em possíveis reflexões e, permita ao leitor realizar as problematizações necessárias no seu campo de atuação, pois reconhece que este estudo pode ampliar discussões e debates na busca em alcançar um ensino mais democrático, crítico, emancipatório e libertador.

\section{Referenciais}

ANDRADE, R. R. M. Pesquisas sobre formação de professores: uma comparação entre os anos 90 e 2000. In: REUNIÃO ANUAL DA ANPED, 1, 2007, Caxambu. Anais [...] Caxambu, 2007.

ANDRÉ, M. Formação de professores: a constituição de um campo de estudos. Revista Educação, Porto Alegre, v. 33, n. 3, p. 174-181, set./dez, 2010.

ANGOTTI, J. A. P.; DELIZOICOV D. Metodologia do Ensino de Ciência. São Paulo: Cortez, 1990.

AUGUSTO, T. G. S.; CALDEIRA, A. M. A. Dificuldades para a implantação de práticas interdisciplinares em escolas estaduais, apontadas por professores da área de Ciências da Natureza. Revista Investigações em Ensino de Ciências, Porto Alegre, v.12, n. 1. p. 139-154, 2007.

AULER, D.; BAZZO, W. A. Reflexões para a implementação do movimento CTA no contexto educacional brasileiro. Revista Ciência \& Educação, Bauru, v. 7, n. 1, p. 1-12, 2001.

AULER, D.; DELIZOICOV, D. Alfabetização Científico-Tecnológica para quê? Revista Ensaio Pesquisa em Educação em Ciências, Belo Horizonte, v. 3, n. 1, p. 122-134, jun, 2001.

BARDIN, L. Análise de conteúdo. São Paulo: Edições 70, 2011.

CACHAPUZ, A. F.; DE PAIXÃO, F. M. La enseñanza de las ciencias y la formación de profesores de enseñanza primaria para la reforma curricular: de la teoría a la práctica. Enseñanza de las ciencias: revista de investigación y experiencias didácticas, v. 17, n. 1, p. 6978, 1999.

CASSIANI, S.; VON LINSINGEN, I. Formação inicial de professores de Ciências: perspectiva discursiva na educação CTS. Educar em Revista, Curitiba, n. 34, p. 127-147, 2009.

CHASSOT, A. Alfabetização Científica: questões e desafios para a Educação. Ijuí: Unijuí, 2000.

CHASSOT, A. Alfabetização científica: uma possibilidade para a inclusão social. Revista Brasileira de Educação, Rio de Janeiro, n. 22, p. 89-100, Jan/Fev/Mar/Abr, 2003.

CHRISPINO, A; LIMA, L. S; ALBUQUeRQUE, M. B; FREITAS, A. C. C; SILVA, M. A. F. B. A área CTS no Brasil vista como rede social: onde aprendemos? Revista Ciência \& Educação, Bauru, v. 19, n. 2, p. 455-479, 2013.

FERREIRA, N. S. A. As pesquisas denominadas "Estado da Arte". Revista Educação \& Sociedade, Campinas, v. 23, n. 79, p. 257- 272, ago. 2002.

FOUREZ, G. Crise no Ensino de Ciências? Revista Investigações em Ensino de Ciências, Porto Alegre, v. 8. n. 2, p. 109-123, 2003. 
FOUREZ, G. Alfabetización científica y tecnológica: acerca de las finalidades de la enseñanza de las ciencias. Buenos Aires, Argentina: Ediciones Colihue, 1994.

FREITAS, L. M.; GHEDIN, E. Pesquisas sobre Estado da Arte em CTS: análise comparativa com a produção em periódicos nacionais. Alexandria - Revista Educação em Ciências e Tecnologia, Florianópolis, v, 8, n. 3, p. 3-25, nov. 2015.

GARVÃO, M. Ensino de Ciências nos Anos Iniciais: dados a partir de um levantamento nas atas do ENPEC. Trabalho de Graduação (Licenciatura em Pedagogia). Universidade Federal da Fronteira do Sul, Chapecó, 2016.

GIL, A. C. Métodos e técnicas de pesquisa social. 6ª edição. São Paulo: Atlas, 2008.

HILÁRIO, T. W.; SOUZA, R. R. Alfabetização Científica nos Anos Iniciais do Ensino fundamental: uma revisão nos últimos ENPEC. In: ENCONTRO NACIONAL DE PESQUISA EM EDUCAÇÃO EM CIÊNCIAS, 11, 2017, Florianópolis, Anais [...] Florianópolis: ABRAPEC, 2017.

LORENZETTI, L. Alfabetização científica no contexto das séries iniciais. 144 f. Dissertação (Mestrado em Educação) - Universidade Federal de Santa Catarina, Florianópolis, 2000.

LORENZETTI, L.; DELIZOICOV, D. Alfabetização Científica no contexto das séries iniciais. Revista Ensaio - Pesquisa em Educação em Ciências, Belo Horizonte, v. 3, n.1, p. 45-61, jun, 2001.

LORENZETTI, L. Estilos de pensamento em educação ambiental: uma análise a partir das dissertações e teses. 2008. Tese (Doutorado em Educação Científica e Tecnológica) Universidade Federal de Santa Catarina, Florianópolis, 2008.

LUZ, R.; ARAÚJO- QUEIROZ, M. B; PRUDÊNCIO, C. A. V. CTS ou CTSA: O Que (Não) Dizem as Pesquisas sobre Educação Ambiental e Meio Ambiente? Alexandria - Revista de Educação em Ciência e Tecnologia, Florianópolis, v. 12. n.1, p.31-54, 2019.

MAMEDE, M.; ZIMMERMANN, E. Letramento científico e CTS na formação de professores para o ensino de física. In: SIMPÓSIO NACIONAL DE ENSINO DE FÍSICA, 16, Rio de Janeiro. Anais [...] Rio de Janeiro, 2005.

MORTIMER, E. F.; MACHADO, A. H. A Linguagem em uma Aula de Ciências. Presença Pedagógica, Belo Horizonte, v. 2, n.11, p. 49-57, 1996.

MOZENA, E. R.; OSTERMANN, F. Uma revisão bibliográfica sobre a interdisciplinaridade no Ensino das Ciências da Natureza. Revista Ensaio, Belo Horizonte, v. 16, n. 2, p. 185-206, 2014.

PIMENTA, S. G.; LISITA, V. M. S. de S. Pesquisas sobre professores e sua formação: uma análise de pesquisas desenvolvidas no programa de Pós-Graduação da FEUSP - 1990 a 1998. Educar em Revista, Curitiba, n. 24, p. 97-109, 2004.

RIBAS, J. F.; BROIETTI, F. C. D. Um estudo da produção escrita de estudantes do Ensino Médio em questões de Ciências do PISA. Amazônia - Revista de Educação em Ciências e em Matemática, Belém, v. 16, n. 36, p. 244-262, 2020.

RODRÍGUEZ, A. S. M.; PINO, J. C. D. Estudo da produção científica sobre o enfoque CTS em revistas brasileiras especializadas. Amazônia - Revista de Educação em Ciências e Matemática, Belém, v. 15, n.33, p. 167-198, jan/jun, 2019.

ROSÁRIO, K. D. S.; VENTURIERI, B.; GUSMÃO, A. Z. A formação de professores de Ciências para os anos iniciais do Ensino Fundamental: análise preliminar nas atas do ENPEC. In: 
ENCONTRO NACIONAL DE PESQUISA EM EDUCAÇÃO EM CIÊNCIAS, 11 2017, Florianópolis, Anais [...], Florianópolis: ABRAPEC, 2017.

SANTOS, W. L. P. Contextualização no ensino de ciências por meio de temas CTS em uma perspectiva crítica. Revista Ciência \& Ensino, Piracicaba, v. 1, número especial, p. 1-12, 2007.

SANTOS, W. L. P dos. Educação CTS e cidadania: confluências e diferenças. Amazônia Revista de Educação em Ciências e em Matemática, Belém, v. 9, n. 17, p. 49-62, jul, 2012.

SANTOS, W. L. P. Educação científica na perspectiva de letramento como prática social: funções, princípios e desafios. Revista Brasileira de Educação, Rio de Janeiro, v. 12, n. 36, p. 474- 492, set./dez. 2007.

SANTOS, W. L. P dos.; MORTIMER, E. F. Uma análise de pressupostos teóricos da abordagem C-T-S (Ciência - Tecnologia - Sociedade) no contexto da educação brasileira. Revista Ensaio - Pesquisa em Educação em Ciências, Belo Horizonte, v. 2, n. 2, p. 110-132, dez., 2002.

SASSERON, L. H. Alfabetização Científica no Ensino Fundamental: estrutura e indicadores deste processo em sala de aula. 2008, 265p. Tese (Doutorado) - Faculdade de Educação, Universidade de São Paulo, São Paulo, 2008.

SASSERON, L. H.; CARVALHO, A. M. P. Alfabetização Científica: uma Revisão Bibliográfica. Revista Investigações em Ensino de Ciências, Porto Alegre, v. 16, n. 1, p. 59-77, 2011.

SLONGO, I. I. P. A produção acadêmica em ensino de biologia: um estudo a partir de teses e dissertações. 2004. Tese (Doutorado em Educação) - Universidade Federal de Santa Catarina, Florianópolis, 2004.

SLONGO, I. I. P.; LORENZETTI, L.; GARVÃO, M. A pesquisa em educação em Ciências disseminada no ENPEC (2007 a 2013): explicitando dados e analisando tendências. In: X ENCONTRO NACIONAL DE PESQUISA EM EDUCAÇÃO EM CIÊNCIAS, 10, Águas de Lindóia Anais [...]. Águas de Lindóia: ABRAPEC, 2015.

SOUSA, F. L. Uma contribuição teórica da utilização da abordagem CTS no Ensino de Ciências. Amazônia - Revista de Educação em Ciências e em Matemática, Belém, v. 9, n. 17, p. 109-121, jun, 2012.

TEIXEIRA, P. M. M.; MEGID NETO, J. A Produção Acadêmica em Ensino de Biologia no Brasil - 40 anos (1972-2011): Base Institucional e Tendências Temáticas e Metodológicas. Revista Brasileira De Pesquisa Em Educação Em Ciências, Belo Horizonte, v. 17, n. 2, p. 521-549, ago., 2017.

TEIXEIRA, P. M. M.; MEGID NETO, J. Investigando a pesquisa educacional: um estudo enfocando dissertações e teses sobre o Ensino de biologia no Brasil. Revista Investigações em Ensino de Ciências, Porto Alegre, v. 11, n. 2, p. 261-282, 2006.

VASCO, A. P. ZAKRZEVSKI, S. B. B. O Estado da Arte das pesquisas sobre Percepção Ambiental no Brasil. Revista Perspectiva, Erechim, v. 34, n. 125, p. 17-28, mar, 2010.

VIECHENESKI, J. P.; LORENZETTI, L.; CARLETTO, M. R. A alfabetização científica nos anos iniciais: uma análise dos trabalhos apresentados nos ENPECs. In: ENCONTRO NACIONAL DE PESQUISA EM EDUCAÇÃO EM CIÊNCIAS, 10, 2015, Águas de Lindóia, Anais [...] Águas de Lindóia: ABRAPEC, 2015. 